\title{
ANALISIS SIKAP KONSUMEN TERHADAP MULTIATRIBUT KOPI BUBUK BINTANG DI KOTA POSO Analysis Of Consumer Attitude To Multiatribut Kopi Bintang in Poso City
}

\author{
Amossius Rompolemba Andi Baso Meringgi ${ }^{1)}$ \\ ${ }^{1}$ Fakultas Pertanian, Universitas Kristen Tentena \\ email: amossiusmerin99i@gmail.com
}

\begin{abstract}
Abstrak
Penelitian ini bertujuan untuk mengetahui : 1). sikap konsumen terhadap multiatribut kopi bubuk merek Bintang; 2) Strategi pemasaran yang dapat dikembangkan oleh Perusahaan Kopi Bintang.

Metode yang digunakan dalam penelitian adalah model sikap Fishbein, menggunakan 4 atribut produk yakni cita rasa, harga, kemasan dan ketersediaan produk. Hasil penelitian menunjukkan bahwa umumnya responden menempatkan cita rasa kopi bubuk sebagai atribut yang paling penting dengan rata-rata nilai 4.07. Atribut kopi bubuk merek Bintang yang memperoleh nilai tertinggi berdasarkan

keyakinan responden adalah atribut kemudahan memperoleh produk dengan rata-rata nilai 3.92 kemudian cita rasa (3.49), harga (3.19) dan kemasan (3.18).

Nilai total sikap konsumen terhadap kopi bubuk Bintang sebesar 52.38, lebih rendah dari nilai total sikap responden terhadap kopi bubuk merek Kapal Api sebesar 55.96.

Kata Kunci: Kopi Bubuk, Sikap, Model Sikap Fishbein, strategi
\end{abstract}

\section{ABSTRACT}

The purpose of this study is to determine consumer attitudes toward Kopi Bintang and to know the marketing strategy. The method used in the study is the Fishbein Attitude Model. This research uses four attributes of a product, those are flavor, price, availability of product, package design. Result of this researc show that Generally, basic on evaluation variabel, respondents choosing flavor as important atribute of powder coffee with the value average is 4.07. Basic on belief variabel, respondents agree that availability of product is good with the value 3.92 than flavor (3.49), price (3.19) and package design (3.18).Total value of attitude by Fishbein model to Bintang coffee powder is 52.38, lower than total value of attitude Kapal Api coffee powder is 55.96.

Keyword: Powder coffee, Attitude, Fishbein model, strategi

\section{PENDAHULUAN}

Kopi bubuk adalah kopi yang biasa tersedia dalam kemasan kertas sampul dan plastik, unggul dalam aroma harum khas kopi yang murni, namun menyisahkan ampas. Terkait dengan kopi telah menjadi salah satu unsur dalam sosial-budaya masyarakat Indonesia maka kopi telah menjadi minuman yang sangat digemari masyarakat. Seiring dengan hal itu, industri pengolahan kopi bubuk olahan di Indonesia pun semakin berkembang dari usaha skala kecil (home industri) hingga usaha pengolahan modern. Perkembangan industri ini ditunjang oleh kesesuain iklim dengan indikator peningkatan luas tanam dan peningkatan produksi sehingga menjadikan Indonesia sebagai produsen kopi terbesar ketiga sekaligus eksportir terbesar keempat di dunia (Pusat Data dan Sistem Informasi Pertanian, 2015). Hal inilah yang menjadi daya tarik tersendiri bagi industri pengolahan kopi sehingga kopi tergolong High value commodity di Indonesia.

Kopi Bintang adalah jenis produk kopi bubuk olahan yang di produksi oleh perusahaan CV. Bintang Harapan Palu Sulawesi Tengah. Kopi Bintang yang diproduksi sejak tahun 1995, masuk dalam area pasar lokal khususnya segmen konsumen tradisional, dengan ciri khas cita rasa lokal dan harga yang terjangkau, bersaing dengan produk Kopi Kapal Api yang menguasai market share pasar kopi bubuk olahan dalam negeri, selain produk-produk yang lebih dulu hadir di pasaran dalam kelas produk yang sama seperti Kopi Singa, Kopi Gelatik maupun Kopi 
Kapten. Kopi Bintang mengandalkan fitur cita rasa yang asli dan harga yang terjangkau yakni Rp. 15.000 untuk kemasan 100 gram dan Rp. 75.000 untuk kemasan 500 gram. Selain melakukan inovasi produk dengan mengembangkan varian kopi bubuk jahe, CV. Bintang Harapan telah mengembangkan strategi pemasaran on-line untuk meningkatkan volume penjualan (www.sultengterkini.com, 2017)

Industri pengolahan kopi yang terus bertumbuh di dalam negeri, karena didukung oleh tersedianya bahan baku yang besar, secara langsung memaksa setiap perusahaan untuk masuk di dalam area persaingan pasar yang ketat. Tingkat persaingan yang cukup ketat mendorong setiap perusahaan tidak terkecuali perusahaan kapal api sebagai pemimpin pasar, terus berkreatif mendesain teknik-teknik pemasaran modern yang dapat di lihat dari beragamnya fitur-fitur produk kopi olahan yang diharapkan dapat memuaskan kebutuhan konsumen, agar dapat bertahan hidup menghadapi perubahan lingkungan ekonomi yang serba cepat dan tak terduga dengan cara menawarkan nilai-nilai pelanggan yang berbeda dengan pesaing. Perusahaan harus bereaksi dan mengantisipasi keinginan pelanggan (Kotler and Keller, 2012; Budica, dkk. 2010).

Mengenali nilai-nilai pelanggan yang dicerminkan oleh bentuk keinginan dan kebutuhan pelanggan adalah kunci utama paradigma pemasaran modern. Fokus utama pemasar adalah kebutuhan dan keinginan konsumen, sehingga tercipta kepuasan pada fihak perusahaan dan pihak konsumen agar pertumbuhan jangka panjang perusahaan dapat terjaga, seperti yang diungkapkan oleh Kotler, dkk., (1999), people need to understand marketing from the point of view of consumers and citizens. Creating customer value and satisfaction are at the very heart of modern marketing thinking and practice. Marketing is the delivery of customer satisfaction at a profit. The goal of marketing is to attract new customers by promising superior value, and to keep current customers by delivering satisfaction.

Keputusan membeli (buying decision) konsumen dapat saja berubah setiap saat sejalan dengan persepsi dan sikapnya terhadap sebuah produk, yang dipengaruhi oleh segala sesuatu yang muncul dari diri konsumen yang disebut perilaku membeli. Menurut Kardes, dkk., (2011) consumer behavior entails all consumer activities associated with the purchase, use, and disposal of goods and services, including the consumer's emotional, mental, and behavioral responses that precede, determine, or follow these activities

Pengamatan terhadap perilaku pembelian konsumen menghasilkan banyak informasi pemasaran antara lain identifikasi siapa konsumen dan kebutuhannya, produk yang dipilih berikut atributnya, termasuk alasan, tempat, kapan dan intensitas pembelian suatu produk (Schiffman and Kanuk, 2008). Secara kognitif, upaya konsumen untuk memenuhi kebutuhan dan keinginan adalah perilaku yang ditampilkan untuk menyelesaikan masalahnya, misalnya dengan mencoba mengumpulkan informasi berbagai produk yang mungkin bisa menyelesaikan masalah yang dihadapinya, menyeleksi informasi itu dan kemudian akan memilih satu merek yang kira-kira sesuai dengan kriteria yang telah ditentukan sebelumnya. Pada konteks inilah konsumen berada pada keputusan bersikap terhadap berbagai varian pilihan yang tersedia.

Sikap adalah kecenderungan pernyataan yang bersifat evaluatif dalam berperilaku dengan cara yang menyenangkan atau tidak menyenangkan terhadap suatu obyek (Robbin dan Judge, 2013). Kemudian obyek yang dimaksud harus ditafsirkan secara luas, meliputi konsep yang berhubungan denga konsumsi atau pemasaran khusus seperti produk, golongan produk, merek, jasa, kepemilikan, penggunaan produk, situs internet, iklan, orang, harga, atau pedagang ritel (Schiffman dan Kanuk, 2008). Beragam produk yang ditawarkan pasar pastinya menciptakan suatu peluang memilih produk yang dirasa memuaskan selera dan kebutuhan konsumen, sehingga terkadang terjadi adanya kecenderungan perubahan sikap konsumen terhadap suatu produk yang telah dikenalnya, serta memilih produk lain yang sesuai dengan kebutuhannya, sehingga terjadinya yang disebut perpindahan merek (Merk switching) akibat dari perubahan sikap konsumen terhadap atribut suatu produk

Lebih lanjut dikatakan oleh Schiffman dan Kanuk (2008) bahwa pembentukan sikap konsumen sangat dipengaruhi oleh pengalaman pribadi, pengaruh keluarga dan teman-teman, pemasaran langsung dan media 
massa. Konsumen membentuk sikap terhadap produk atau merek melalui proses integrasi konsumen yaitu mengkombinasikan beberapa beberapa pengetahuan, arti dan kepercayaan tentang produk dan merek untuk membentuk evaluasi menyeluruh. Melalui berbagai pengalaman konsumen mendapatkan berbagai kepercayaan tentang produk. Karena kapasitas kognitif seseorang terbatas, hanya sebagian kecil dari kepercayaan ini yang dapat diaktifkan. Kepercayaan yang diaktifkan disebut kepercayaan utama yaitu sesuatu yang diaktifkan pada saat tertentu dan dalam konteks tertentu. Hanya kepercayaan utama yang menyebabkan atau menciptakan sikap seseorang terhadap objek tertentu (Simamora, 2003). Dan segala sesuatu yang mempengaruhi konsumen untuk bersikap disebut objek sikap (Solomon, 2006).

Berdasarkan pada prinsip tentang tujuan perusahaan untuk memenuhi keinginan dan kebutuhan konsumen yang dapat dipelajari melalui sikap konsumen ketika menghadapi pilihan produk yang sesuai dengan kebutuhannya, maka perusahaan dapat menciptakan strategi pemasaran yang efektif dan efisien. Kotler (1997) mendefenisikan strategi pemasaran sebagai suatu perangkat asas-asas yang konsekuen, tepat dan layak (feasible), yang oleh suatu perusahaan tertentu diharapkan akan memungkinkannya untuk mencapai tujuannya dalam hal pelanggan dan penghasilan laba dalam suatu lingkungan persaingan tertentu. Berkaitan dengan sikap konsumen, beberapa strategi pengubahan sikap yang dapat dilakukan pemasar adalah :

1. Mengubah fungsi motivasi dasar

Strategi yang efektif untuk mengubah sikap konsumen terhadap produk merek tertentu adalah membuat berbagai kebutuhan tertentu menonjol. Salah satu metodenya adalah pendekatan fungsional, yaitu sikap dapat digolongkan menurut empat fungsi, yaitu fungsi manfaat, fungsi pembelaan ego, fungsi pernyataan nilai, fungsi pengetahuan, menggabungkan beberapa fungsi

2. Menghubungkan produk dengan golongan, peristiwa, atau kegiatan amal tertentu

3. Memecahkan masalah dua sikap yang bertentangan

4. Mengubah komponen model multi sifat, yang terdiri dari mengubah penilaian relatif terhadap sikap, mengubah keyakinan terhadap merek, menambah sifat, merubah peringkat penilaian terhadap mereka secara keseluruhan

5. Mengubah keyakinan terhadap merek pesaing.

Tentunya hal ini menjadi tantangan tersendiri bagi Kopi Bintang dalam mempertahankan pelanggannya dan bisa bertahan di dalam pasar yang peka terhadap perubahan dalam persaingan yang sangat ketat Berdasarkan latarbelakang tersebut maka penelitian ini bertujuan untuk :

a. Mengetahui sikap konsumen terhadap produk Kopi Bintang

b. Mengetahu strategi pemasaran produk Kopi Bintang yang dapat diterapkan

\section{METODE PENELITIAN}

Penelitian ini adalah jenis penelitian survey eksplanatory, yang dilaksanakan di Poso City Mall dan BNS Mart Poso, pada bulan Mei hingga Agustus 2017. Data yang dikumpulkan adalah data primer, yang diperoleh dengan bantuan angket yang bersifat tertutup.

Populasi penelitian adalah konsumen yang mengkonsumsi kopi bubuk, dan dipilih dengan cara accidental sampling. Konsumen yang dijumapi di lokasi penelitin yang kebetulan sedang membeli kopi bubuk Bintang dijadikan sampel penelitian berjumlah 100 orang.

Variabel penelitian adalah evaluasi dan keyakinan. Indikator yang digunakan untuk mengetahui sikap responden terhadap masingmasing variabel adalah atribut produk kopi bubuk cita rasa, harga, kemasan dan ketersediaan produk. Sikap responden terhadap evaluasi kepentingan dinyatakan dalam skala angka :

$$
\begin{aligned}
& 5=\text { Sangat penting } \\
& 4=\text { Penting } \\
& 3=\text { Biasa } \\
& 2=\text { Tidak penting } \\
& 1=\text { Sangat tidak penting }
\end{aligned}
$$

Sikap responden terhadap keyakinan kopi bubuk merek Bintang dan merek Kapal Api memiliki atribut cita rasa, harga, kemasan dan ketersediaan produk dinyatakan dalam skala angka :

$$
\begin{aligned}
& 5=\text { Sangat setuju } \\
& 4=\text { Setuju } \\
& 3=\text { Biasa } \\
& 2=\text { Tidak setuju } \\
& 1=\text { Sangat tidak setuju }
\end{aligned}
$$


Untuk mengetahui sikap responden, data dianalisis menggunakan Model Fishbein, yang didasarkan pada pemikiran bahwa kepercayaan (belief) dan perasaan (feelings) akan mempengaruhi sikap, dengan menggunakan rumus :

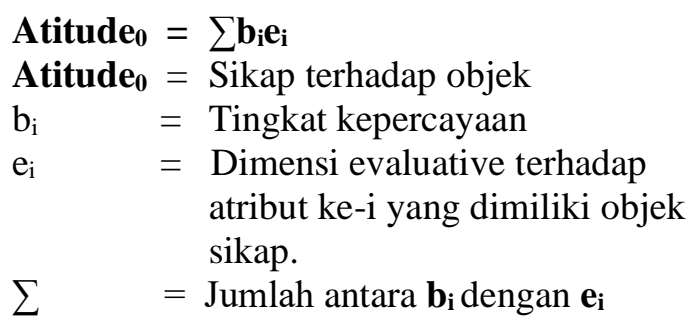

Untuk mengetahui strategi pemasaran, maka sikap responden yang diketahui melalui

Tabel 1. Evaluasi tingkat kepentingan atribut produk kopi bubuk (ei)

\begin{tabular}{|l|c|c|c|c|c|c|}
\hline \multicolumn{1}{|c|}{ Atribut } & \multicolumn{3}{c|}{ Skor tingkat evaluasi atribut (ei) } & \multirow{2}{*}{ Rata-rata } \\
\hline & $\mathbf{5}=$ sangat penting; $\mathbf{1}=$ Sangat tidak penting & \\
\hline Cita rasa & $\mathbf{5}$ & $\mathbf{4}$ & $\mathbf{3}$ & $\mathbf{2}$ & $\mathbf{1}$ & \\
\hline Harga & 32 & 49 & 14 & 4 & 1 & $\mathbf{4 . 0 7}$ \\
\hline Kemasan & 20 & 49 & 19 & 10 & 2 & $\mathbf{3 . 7 5}$ \\
\hline Kemudahan memperoleh produk & 14 & 20 & 35 & 26 & 5 & $\mathbf{3 . 1 2}$ \\
\hline
\end{tabular}

Tabel 2. Frekwensi skor tingkat kepercayaan atribut kopi bubuk Bintang (bi)

\begin{tabular}{|l|c|c|c|c|c|c|}
\hline \multirow{2}{*}{ Atribut } & \multicolumn{4}{|c|}{ Skor tingkat kepercayaan (bi) atribut } & \multirow{2}{*}{ Rata-rata } \\
\cline { 2 - 7 } & $\mathbf{5 =}$ sangat setuju; $\mathbf{1}$ Sangat tidak setuju & $\mathbf{1}$ \\
\hline Cita rasa & $\mathbf{5}$ & $\mathbf{4}$ & $\mathbf{3}$ & $\mathbf{2}$ & $\mathbf{1}$ & \\
\hline Harga & 20 & 27 & 38 & 12 & 3 & $\mathbf{3 . 4 9}$ \\
\hline Kemasan & 12 & 24 & 39 & 21 & 4 & $\mathbf{3 . 1 9}$ \\
\hline Kemudahan memperoleh produk & 19 & 16 & 33 & 28 & 4 & $\mathbf{3 . 1 8}$ \\
\hline
\end{tabular}

Tabel 3. Frekwensi skor tingkat kepercayaan atribut kopi bubuk Kapal Api (bi)

\begin{tabular}{|l|c|c|c|c|c|c|}
\hline \multirow{3}{*}{ Atribut } & \multicolumn{5}{|c|}{ Skor tingkat kepercayaan (bi) atribut } & \multirow{2}{*}{ Rata-rata } \\
\cline { 2 - 6 } & $\mathbf{5}=$ sangat setuju; $\mathbf{1}$ = Sangat tidak setuju & \multirow{2}{*}{$\mathbf{5}$} \\
\cline { 2 - 6 } & 35 & 29 & 24 & 6 & 6 & $\mathbf{3 . 8 1}$ \\
\hline Cita rasa & 28 & 38 & 25 & 7 & 2 & $\mathbf{3 . 8 3}$ \\
\hline harga & 12 & 22 & 45 & 22 & 3 & $\mathbf{3 . 3}$ \\
\hline kemasan & 34 & 45 & 15 & 4 & 2 & $\mathbf{4 . 0 5}$ \\
\hline Kemudahan memperoleh produk & & & & & \\
\hline
\end{tabular}

Tabel 4. Hasil analisis sikap multiatribut Fishbein kopi bubuk Bintang dan Kapal Api

\begin{tabular}{|c|c|c|c|c|c|}
\hline \multirow{3}{*}{ Atribut } & \multirow{3}{*}{$\begin{array}{c}\begin{array}{c}\text { Skor evaluasi } \\
\text { kepentingan }\end{array} \\
\text { ei }\end{array}$} & \multicolumn{4}{|c|}{ Skor kepercayaan (bi) } \\
\hline & & \multicolumn{2}{|c|}{ BINTANG } & \multicolumn{2}{|c|}{ KAPAL API } \\
\hline & & bi & ei.bi $=\mathbf{A o}$ & bi & ei.bi $=$ Ao \\
\hline Cita rasa & 4.07 & 3.49 & 14.20 & 3.81 & 15.51 \\
\hline Harga & 3.75 & 3.19 & 11.96 & 3.83 & 14.36 \\
\hline Kemasan & 3.12 & 3.18 & 9.92 & 3.3 & 10.30 \\
\hline Kemudahan memperoleh produk & 3.9 & 3.92 & 15.29 & 4.05 & 15.80 \\
\hline$\Sigma$ bi ei & & & 52.38 & & 55.96 \\
\hline
\end{tabular}

Tabel 1 menunjukkan bahwa menurut tingkat kepentingan atribut terhadap produk 
kopi bubuk, responden tetap memilih cita rasa sebagai atribut yang penting pada sebuah produk kopi bubuk dengan nilai rata-rata 4.07. Cita rasa kopi dirasakan langsung oleh konsumen dan sangat berkaitan erat dengan selera masyarakat mengkonsumsi kopi bubuk oleh sebab itu konsumen yang memperoleh stimuli yang bersifat evaluasi, akan bersikap positif atau negatif terhadap sebuah produk kopi bubuk. Selain itu, kebiasaan mengkonsumsi kopi setiap hari di kalangan masyarakat menyebabkan responden memilih atribut ketersediaan produk pada urutan kedua kepentingan atribut yang penting dengan ratarata nilai 3.9. Pada Atribut harga dengan ratarata nilai 3.75 mengindikasikan bahwa terdapat responden yang mementingkan faktor harga dan ada yang tidak, namun dapat saja faktor harga juga turut mempengaruhi kinerja penjualan produk bila dihubungkan dengan faktor ekonomi. Kemasan adalah atribut luar dari sebuah produk namun dalam hal ini, responden menganggap kemasan hanyalah bagian dari sebuah produk yang dianggap biasa saja tetapi juga bukan berarti tidak penting berdasarkan rata-rata nilai 3.12.

Pada tabel 2 dan 3 memperlihatkan keyakinan responden bahwa produk kopi bubuk Bintang (3.92) dan Kapal Api (4.05) selalu tersedia ketika mereka ingin membelinya sehingga nilai rata-rata atribut ini terhadap kopi bubuk Bintang dan Kapal Api lebih tinggi dibanding ketiga atribut lainnya. Pada atribut cita rasa, rata-rata nilai 3.49 menunjukkan anggapan responden bahwa cita rasa kopi bubuk Bintang berada pada kategori biasa bila dibandingkan dengan kopi bubuk Kapal Api yang memperoleh rata-rata nilai 3.81 atau responden setuju bahwa kopi Kapal Api memiliki cita rasa yang lebih baik menurut selera mereka. Hal ini ditegaskan oleh pilihan responden terhadap atribut harga, sebagai indikator bahwa kualitas produk pada aspek cita rasa berbawaan dengan harga produk.

Secara keseluruhan sikap responden terhadap multiatribut kopi bubuk merek Bintang dan Kapal Api ditampilkan pada tabel 4. Sikap responden ditunjukkan oleh sikap total yaitu 52.38 untuk kopi merek Bintang dan 55.96 untuk kopi merek Kapal Api. Nilai total sikap responden terhadap kopi Bintang yang lebih rendah menunjukkan bahwa responden kurang menyukai kopi Bintang.
Sikap dipengaruhi oleh pengalaman menggunakan sebuh merek dan menjadi stimulus terhadap keputusan pembelian kopi Bintang. Namun kelemahan dalam penelitian ini adalah tidak melakukan analisis lebih jauh untuk mengetahui keputusan pembelian oleh responden terkait dengan sikap mereka.

Sikap responden ini menyatakan bahwa mereka tidak memperoleh sesuatu yang mereka inginkan dari kopi Bintang dan ini dapat menjadi dasar keputusan pembelian sehingga dapat mempengaruhi kinerja pemasaran kopi Bintang yang lebih kuat untuk bersaing dengan produk kopi bubuk lainnya.

Pengalaman konsumen dalam menggunakan suatu produk akan menciptakan sikap, baik itu positif berupa pembelian ulang dan keloyalan terhadap merek maupun negatif dalam bentuk merk switching atau pindah merek. Menurut Engel, et. al (1994), pembelian suatu produk oleh konsumen merupakan fungsi dari dua faktor, yaitu niat pembelian dan pengaruh lingkungan dan/atau perbedaan individual. Selanjutnya, perilaku proses keputusan tidak berhenti begitu konsumen membeli suatu produk, tetapi konsumen akan melakukan evaluasi pascapembelian, yang berbentuk membandingkan kinerja produk berdasarkan harapan yang dia inginkan, dan hasil evaluasi pascapembelian adalah kepuasan atau ketidakpuasan.

Menurut Schiffman dan Kanuk (2008), dari sudut pengkondisian klasik, merek yang sudah mapan merupakan stimulus yang tidak terkondisi, yang melalui penguatan positif telah menimbulkan sikap yang menyenangkan terhadap merek. Hal ini semakin menguatkan konsep dasar sikap bahwa pembelian akan mempengaruhi sikap, dan penilaian responden secara keseluruhan dapat menjadi faktor yang dapat mempengaruhi stimulus masyarakat untuk melakukan pembelian karena kebutuhan mereka terhadap konsumsi kopi dapat dipenuhi oleh produk-produk kopi yang lain di pasaran seperti Kapal Api, Torabika, Indocoffee dan lain-lain.

Apa yang berlaku dalam pembentukan sikap pada dasarnya juga berlaku dalam perubahan sikap. Perubahan sikap dipelajari dalam kaitannya dengan strategi yang akan digunakan dalam pemasaran produk atau jasa. Dasar strateginya bertumpu pada tujuan untuk "mengubah sikap konsumen". Bagi produk 
yang telah menjadi pemimpin pasar maka tujuannya adalah semakin memperkuat sikap positif para konsumen yang sudah ada agar tidak beralih terhadap berbagai penawaran khusus para pesaing yang menawarkan produk baru yang mungkin sama untuk memenangkan mereka. Kopi kapal api yang saat ini menjadi market leader untuk produk kopi bubuk pun tetap mengembang strategi iklan (Jingle iklan Jelas lebih enak ) menggunakan strategi "mengubah keyakinan terhadap merek" dengan tujuan menjaga dan memperkuat brand image kapal api dimata pelanggan.

Responden tidak atau belum yakin bahwa Kopi Bintang dapat memenuhi keinginan atau selera mereka, kemudian dihubungkan dengan prinsip strategi pengubahan sikap, maka strategi yang dapat dijalankan oleh pemasar Kopi Bintang didasarkan pada prinsip memecahkan masalah dua sifat yang bertentangan dan mengubah keyakinan terhadap merek dengan tujuan untuk mengubah sikap terhadap kopi Bintang.

Bila didasarkan pada evaluasi dan keyakinan terhadap multiatribut dan total sikap responden terhadap kopi Bintang, strategi yang dapat diterapkan oleh perusahaan kopi Bintang adalah :

a. Memecahkan masalah dua sifat yang bertentangan

Strategi pengubahan sikap kadang-kadang dapat memecahkan konflik aktual atau potensial antara dua sikap jika konsumen dapat diyakinkan bahwa sikap mereka yang negatif terhadap produk sebetulnya tidak bertentangan dengan sikap yang lain. Misalnya, konsumen suka dengan kopi yang bercita rasa tinggi, tetapi tidak yakin bahwa Kopi Bintang memiliki cita rasa yang sesuai dengan seleranya. Mereka mungkin dapat dibujuk untuk mengubah penilaian mereka terhadap Kopi Bintang.

b. Mengubah keyakinan terhadap merek Strategi ini lebih berorientasi kognitif, yang dipusatkan untuk mengubah keyakinan atau persepsi terhadap merek, dan merupakan bentuk yang paling umum untuk daya tarik iklan, yang berusaha mengingatkan konsumen bahwa produk A "lebih" atau "lebih baik" dari sudut beberapa sifat produk yang penting. Bentuk strategi ini digunakan oleh pemasar produk kopi Kapal Api.

c. Pemasaran langsung (Direct selling)
Salah satu bentuk strategi yang efektif dijalankan untuk mengubah sikap adalah pemasaran langsung, sebab sarana utama terbentuknya sikap terhadap barang atau jasa adalah melalui pengalaman langsung konsumen dalam mencoba dan menilai barang atau jasa tersebut. Menurut Schiffman dan Kanuk (2008) hal ini dapat dilakukan dengan cara pemberian kupon pengurangan harga atau contoh gratis. Tujuannya adalah membujuk konsumen untuk mencoba produk dan kemudian menilainya. Jika ternyata suatu produk mereka sukai, maka konsumen mungkin akan membentuk sikap positif serta melakukan pembelian produk.

Strategi pemasaran langsung ini juga dapat pula didukung oleh unsur penguatan strategi melalui segmentasi pasar Kopi Bintang pada konsumen tradisional, yaitu orang-orang yang senang minum kopi tubruk (kopi murni), biasanya dikonsumsi pada pagi hari sebelum beraktifitas, saat santai, atau pada acara keluarga.

\section{KESIMPULAN}

Responden menganggap cita rasa adalah atribut produk kopi bubuk yang paling penting dibanding ketiga atribut lainnya. Responden lebih memilih atribut kemudahan memperoleh produk kopi bubuk merek Bintang dibanding atribut cita rasa, harga dan kemasan, berbanding terbalik dengan rata-rata nilai evaluasi responden terhadap kopi bubuk yang menempatkan cita rasa pada nilai tertinggi. Oleh karena itu, pemasar kopi Bintang harus meningkatkan kualitas atribut cita rasa kopi Bintang agar dapat memenuhi keinginan dan kebutuhan konsumen yang tergambar pada variabel evaluasi.

Perusahaan kopi bubuk Bintang dapat mengembangkan strategi pemasaran dengan menggunakan prinsip memecahkan masalah dua sifat yang bertentangan melalui pengubahan sikap, mengubah keyakinan terhadap merek serta Pemasaran langsung.

\section{DAFTAR PUSTAKA}

Budica, Ilie., Silvia Puiu, Bogdan Andrei Budica, 2010. CONSUMER BEHAVIOR. Annals of the constantin brâncuşi university of târgu jiu, economy series, issue 1/2010 
Engel, B, James. F, Blackwell, Roger D., dan Miniard, Paul W., Perilaku Konsumen, Alih bahasa Budiyanto, Binarupa Aksara, Jakarta, 1994.

John.C Mowen and Michael Minor. 2002. Perilaku

Konsumen. Erlangga.Jakarta

Kardes, Frank R., Maria L. Cronley, Thomas W. Cline, 2011. CONSUMER BEHAVIOR. Western Cengage Learning, Mason USA

Kotler, Philip., Kevin Lane Keller, 2012. MARKETING MANAGEMENT. 14 ed, Prentice-Hall, Inc.,USA

Kotler, Philip., 2009. PRINCIPLES OF MARKETING. 2 ed, Prentice-Hall, Inc.,USA

Robbins, Stephen P., Timothy A. Judge, 2013. Organizational behavior. 15th ed. Prentice Hall USA

Shiffman.L, Kanuk.LL. 2008. Perilaku Konsumen. Ed. Ketujuh. PT.Indeks. Jakarta

Setiadi, N.J. 2003. Perilaku Konsumen. Strategi dan Implikasi untuk Strategi dan Penelitian Pemasaran. Grenada Media, Jakarta.

Simamora. 2003. Memenangkan Pasar dengan Pemasaran Efektif dan Profitabel. PT. Gramedia Pustaka Utama, Jakarta.

Sutisna. 2001. Perilaku Konsumen dan Komunikasi Pemasaran. PT. Remaja Rosdakarya, Bandung.
2002. Perilaku Konsumen dan Strategi Pemasaran, Rosdakarya, Bandung,

Solomon, Michael., Gary Bamossy, Søren Askegaard, Margaret K. Hogg, 2006. CONSUMER BEHAVIOUR; A European Perspective. Prentice-Hall, Inc.,USA

Winardi, J., 2012. MANAJEMEN PERILAKU ORGANISASI. Cetakan 4, Penerbit Kencana, Jakarta 
